Published in final edited form as:

J Am Chem Soc. 2008 December 24; 130(51): 17206-17207. doi:10.1021/ja806668q.

\title{
Structure of (E)-4-Hydroxy-3-methyl-but-2-enyl Diphosphate Reductase, the Terminal Enzyme of the Non-Mevalonate Pathway
}

\author{
Ingo Rekittke ${ }^{\dagger}$, Jochen Wiesner ${ }^{\star}, \dagger$, Rene Röhrich ${ }^{\dagger}$, Ulrike Demmer ${ }^{\ddagger}$, Eberhard Warkentin ${ }^{\ddagger}$, \\ Weiya Xu§, Kathrin Troschke ${ }^{\dagger}$, Martin Hintz ${ }^{\dagger}$, Joo Hwan Noll, Evert C. Duin $\S$, Eric \\ Oldfield $^{*}, \|, \perp$, Hassan Jomaa ${ }^{\dagger}$, and Ulrich Ermler ${ }^{*}, \ddagger$ \\ †Institut für Klinische Immunologie and Transfusionsmedizin, Justus-Liebig-Universität Giessen, \\ Langhansstrasse 7, 35385 Giessen, Germany \\ ‡Max Planck Institute für Biophysik, Max-Von-Laue-Strasse 3, D-60438 Frankfurt am Main, \\ Germany \\ $\S$ Department of Chemistry and Biochemistry, Auburn University, 179 Chemistry Building, Alabama \\ 36849 \\ "Center for Biophysics and Computational Biology, 607 South Mathews Avenue, Urbana, Illinois \\ 61801 \\ ${ }^{\perp}$ Department of Chemistry, University of Illinois at Urbana-Champaign, 600 South Mathews \\ Avenue, Urbana, Illinois 61801
}

\begin{abstract}
In all organisms studied so far, isoprenoids such as dolichol, ubiquinones, carotenoids, and sterols are synthesized from isopentenyl diphosphate (IPP) and its isomer, dimethylallyl diphosphate (DMAPP). However, there are two completely different biosynthetic pathways leading to these two precursor molecules. In animals, fungi, archaea, and some bacteria, IPP and DMAPP are synthesized via the well-known mevalonate pathway. In contrast, the vast majority of bacteria, and some parasitic protozoa of the phylum Apicomplexa, synthesize IPP and DMAPP via the 2-C-methyl-o-erythritol-4-phosphate (MEP) pathway [also known as the 1-deoxy-d-xylulose-5-phosphate (DOXP), or non-mevalonate pathway]. ${ }^{1-3}$ Since the MEP pathway is not used by humans, it represents an attractive target for the development of new antimicrobial compounds and indeed, inhibitors of the second enzyme of the MEP pathway, DOXP reductoisomerase, have demonstrated good antibacterial as well as antimalarial activity, in clinical settings. ${ }^{4-6}$ Both IPP and DMAPP are formed (in a 5:1 ratio) in the last step of the MEP pathway from the substrate (E)-4-hydroxy-3-methyl-but-2-enyl diphosphate (HMBPP) in the following reaction:
\end{abstract}

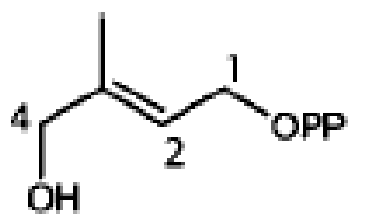

HMBPP
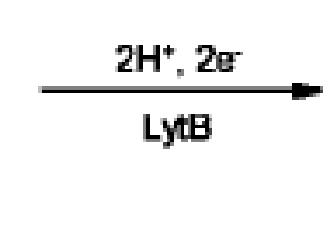
catalyzed by the enzyme HMBPP reductase, also known as LytB or IspH. ${ }^{7}$ The reaction is thought to involve an iron-sulfur cluster reducing HMBPP to an allylic anion, followed by protonation at either $\mathrm{C} 2$ or $\mathrm{C} 4$, to form IPP or DMAPP. ${ }^{8}$ However, the three-dimensional structure of the LytB enzyme has not yet been reported, making mechanistic analyses more challenging. Here, we report the X-ray crystallographic structure of the LytB enzyme from Aquifex aeolicus and propose a structure-based model for catalysis.

We first discuss several features of LytB sequences in general that might be expected to be of importance for substrate binding and catalysis by considering the sequence homology between 224 LytB enzymes as annotated by the JPRED3 program. $^{9}$ There are three totally conserved cysteines in the A. aeolicus sequence that anchor the catalytically active iron-sulfur cluster: Cys13, Cys96, and Cys193 (Figure 1 and Supporting Information, Figure S1). HMBPP can be expected to bind to the iron-sulfur cluster during catalysis via its $\mathrm{O} 4$ atom, but it also needs to bind to protein residues and related diphosphates typically bind to prenyl synthase enzymes either via a DDXXD motif or via electrostatic/hydrogen bond interactions with Lys, Arg, or His. On the basis of the sequence alignment (Supporting Information Figure S1) we find neither evidence for DDXXD clusters, consistent with the lack of a requirement for $\mathrm{Mg}^{2+}$, nor totally conserved Lys or Arg residues or even totally conserved Lys/Arg positions. There are, however, two highly conserved His residues, $\mathrm{H} 42$ and H124. These two conserved His were reported in 10 putative LytB sequences by Adam et al. ${ }^{11}$ and are now seen in all 224 sequences. This strongly suggests that the diphosphate binds to $\mathrm{H} 42$ and $\mathrm{H} 124$. The third feature that would be expected for LytB is the presence of a totally conserved residue (or residues) that would be involved as proton donor(s) to $\mathrm{C} 2$ or $\mathrm{C} 4$. On the basis of the sequence alignments, we see that there is just a single totally conserved acidic residue, E126. So, based on these arguments, we expect LytB structures to contain an iron-sulfur cluster coordinated to Cys13, Cys96, and Cys193, with His 42 and His124 being on the order of the length of HMBPP ( 11 $\AA$ ) distant from the cluster, permitting the HMBPP diphosphate to bind electrostatically. If E126 is a proton donor to the allylic anion formed on reduction of HMBPP, E126 also needs to be appropriately positioned to enable $s i$-face attack on the double bond, producing the major product, IPP. And, on the basis of the sequence predictions, we anticipate a highly $\alpha / \beta$ protein (Supporting Figure S1).

We determined the single crystal X-ray structure of LytB from A. aeolicus at $1.65 \AA$ resolution $\left(R_{\text {free }}=22.8 \%\right)$ using anaerobically grown crystals. Data collection and refinement statistics are reported in Supporting Information, Table S1. Each monomer has a cloverleaf structure built up of $\alpha / \beta$ domains surrounding a central $\mathrm{Fe}_{3} \mathrm{~S}_{4}$ cluster (Figure $2 \mathrm{~A}, \mathrm{~B}$ ), and represents a novel fold. The structure is quite flat (Figure 2B) but there is a pronounced ca. $10 \AA \times 20 \AA$ cavity at the front side (Figure 2C), flanked by the conserved His42, His124, Thr166, and Ser265 (Figure 2C, in blue), enabling substrate access/product egress. The Fe/S cluster (brown/ yellow) is located at the bottom of the crevice, while the backside of the protein shows no obvious substrate access route (Figure 2D).

But how does this structure help us to begin to understand the mechanism of action of LytB? To date, we have not been successful in cocrystallizing LytB with HMBPP. Moreover, the crystal structure obtained has an $\mathrm{Fe}_{3} \mathrm{~S}_{4}$ cluster, while activated LytB (from E. coli) is thought to contain an $\mathrm{Fe}_{4} \mathrm{~S}_{4}$ cluster. ${ }^{8}$ The structure nevertheless provides all of the information necessary to test the ideas suggested from the sequence homology results as to the likely roles of the conserved His and Glu residues. Specifically, it should be possible to test if HMBPP can be docked to the LytB structure in such a way that when its $\mathrm{O} 4$ atom is adjacent to the $\mathrm{Fe} / \mathrm{S}$ cluster, the putative His42 and His124 PPi-binding residues can in fact interact with the HMBPP diphosphate. Plus, it should be possible to test whether the putative proton donor (E126) is in fact nearby, as well as being appropriately placed for si-face protonation. To test these hypotheses, we reconstituted the $\mathrm{Fe}_{3} \mathrm{~S}_{4}$ cluster computationally to form the $\mathrm{Fe}_{4} \mathrm{~S}_{4}$ species, 
then used the Glide program ${ }^{12}$ to position HMBPP into the active site. As can be seen in Figure 3, HMBPP can readily bind with its diphosphate oxygens interacting with His42 and His124 while the HMBPP O4 is located $\sim 1.9 \AA$ A from the fourth $\mathrm{Fe}$.

Support for this binding mode is also obtained from the location of E126. As noted above, this is the only totally conserved acidic residue, and as such, it is a likely candidate for a proton donor. As can be seen in Figure 3, the carboxyl group of E126 is $\sim 4 \AA$ from C2 of HMBPP, meaning that the carboxyl proton would be only $\sim 2 \AA$ from its final position in the IPP product. This close proximity supports a role in protonating $\mathrm{C} 2$ of the allylic species. Moreover, being positioned below the double bond results in $s i$-face attack, as found experimentally. On the basis of the structure and on the multiple sequence alignment results, we find no other candidates for protonating $\mathrm{C} 4$, so it seems likely that E126 may again be involved, with the ca. 5:1 IPP/DMAPP product ratio being related to the E126 side-chain conformations.

\section{Supplementary Material}

Refer to Web version on PubMed Central for supplementary material.

\section{Acknowledgments}

This work was supported by the Max-Planck Society and in part by the United States Public Health Service (NIH grant GM07326 to E.O.). We thank Hartmut Michel for continuous support and the staffs of PXII at the Swiss Light Source (Villigen), in particular, Anuschka Pauluhn, for help during data collection. We thank Robert M. Coates, Wilfred A. van der Donk, Thomas B. Rauchfuss, and Dushyant Mukkamala for helpful comments.

\section{References}

1. Horbach S, Sahm H, Welle R. FEMS Microbiol Lett 1993;111:135-140. [PubMed: 8405922]

2. Arigoni D, Sagner S, Latzel C, Eisenreich W, Bacher A, Zenk MH. Proc Natl Acad Sci U S A 1997;94:10600-10605. [PubMed: 9380681]

3. Sprenger GA, Schorken U, Wiegert T, Grolle S, de Graaf AA, Taylor SV, Begley TP, Bringer-Meyer S, Sahm H. Proc Natl Acad Sci U S A 1997;94:12857-12862. [PubMed: 9371765]

4. Kuemmerle HP, Murakawa T, Sakamoto H, Sato N, Konishi T, De Santis F. Int J Clin Pharmacol Ther Toxicol 1985;23:521-528. [PubMed: 4066076]

5. Jomaa H, Wiesner J, Sanderbrand S, Altincicek B, Weidemeyer C, Hintz M, Turbachova I, Eberl M, Zeidler J, Lichtenthaler HK, Soldati D, Beck E. Science 1999;285:1573-1576. [PubMed: 10477522]

6. Missinou MA, Borrmann S, Schindler A, Issifou S, Adegnika AA, Matsiegui PB, Binder R, Lell B, Wiesner J, Baranek T, Jomaa H, Kremsner PG. Lancet 2002;360:1941-1942. [PubMed: 12493263]

7. Rohdich F, Hecht S, Gartner K, Adam P, Krieger C, Amslinger S, Arigoni D, Bacher A, Eisenreich W. Proc Natl Acad Sci U S A 2002;99:1158-1163. [PubMed: 11818558]

8. Wolff M, Seemann M, Tse Sum Bui B, Frapart Y, Tritsch D, Garcia Estrabot A, Rodriguez-Concepcion M, Boronat A, Marquet A, Rohmer M. FEBS Lett 2003;541:115-120. [PubMed: 12706830]

9. Cuff JA, Clamp ME, Siddiqui AS, Finlay M, Barton GJ. Bioinformatics 1998;14:892-893. [PubMed: 9927721]

10. Thompson JD, Gibson TJ, Plewniak F, Jeanmougin F, Higgins DG. Nucleic Acids Res 1997;25:48764882. [PubMed: 9396791]

11. Adam P, Hecht S, Eisenreich W, Kaiser J, Grawert T, Arigoni D, Bacher A, Rohdich F. Proc Natl Acad Sci U S A 2002;99:12108-12113. [PubMed: 12198182]

12. Glide, version 4.5. Schrodinger, LLC; New York, NY: 2007. 
Aquifex aeolicus Helicobacter pylori Chlorobium tepidum Clostridium difficile Escherichia coli Yersinia pestis

Pseudomonas aenuginosa Mycobacterium tuberculosis Plasmodium falciparum Bacillus anthracis
$*: * * *::$ : $:: * *$ AGFCFGVKRAVKLAEESLKESQGK - -VYTLGPI IHNPQE YGFCFGVKRAIQIAEKNQNS - - - - -LIFGSLIHNAKE SGFCIGVQGT IHVAEEKLAQS-GE- - LYCLGDVVHNEVE AGFCFGVKRAMKMAWDEVEKNDSG - - I YALGPL I HNKQA RGFCAGVDRAISIVENALA I YGAP - - I YVRHEVVHNRYV RGFCAGVDRAIS IVERAIEMYGAP - I IVRHEVVHNRYV RGFCAGVDRAIEIVNRALDVFGPP - I I YVRHEVVHNKFV RGYCAGVDRAVETVERALQKHGPP - - VYVRHEIVHNRHV RGFCKGVSRAIETVEECLKLFKPP - - I YVKHKIVHNDIV RGYCYGVVDAMVIARNAALDTSLPRP I Y ILGMIVHNKHV

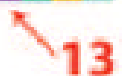

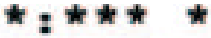
(1) DATCPYVKAVHEAVCQLTREGYFVVLVGEKNHPEVIGTLG DATCPYVIKPQQIVESMSKEGYQIVLFGDINHPEVKGVIS DTTCPVVAKLQRTAKMLHQLGYQVVIYGKKVHPEVIGING DTTCPFVKK I HTVVSEYHNKGYE I IVI GDMKHP EVI GING DATCPLVTKVHMEVARASRRGEESILIGHAGHP EVEGTMG DATCPLVTKVHMEVARASRKGKEAILIGHAGHPEVEGTMG DATCPLVTKVHMEVVRY SRDGHECVLI GHEGHPEVEGTMG DATCPLVTKVHNEARRFARDDYDILLIGHEGHEEVVGTAG DATCPLVNKVHVYVQMKAKENYDI ILIGYKNHVEVIGTYN DATCPDVTKTHDLIEAKKAEGYHVIYIGKKNHPEP EGAVG

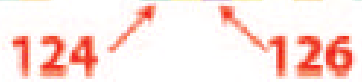

42
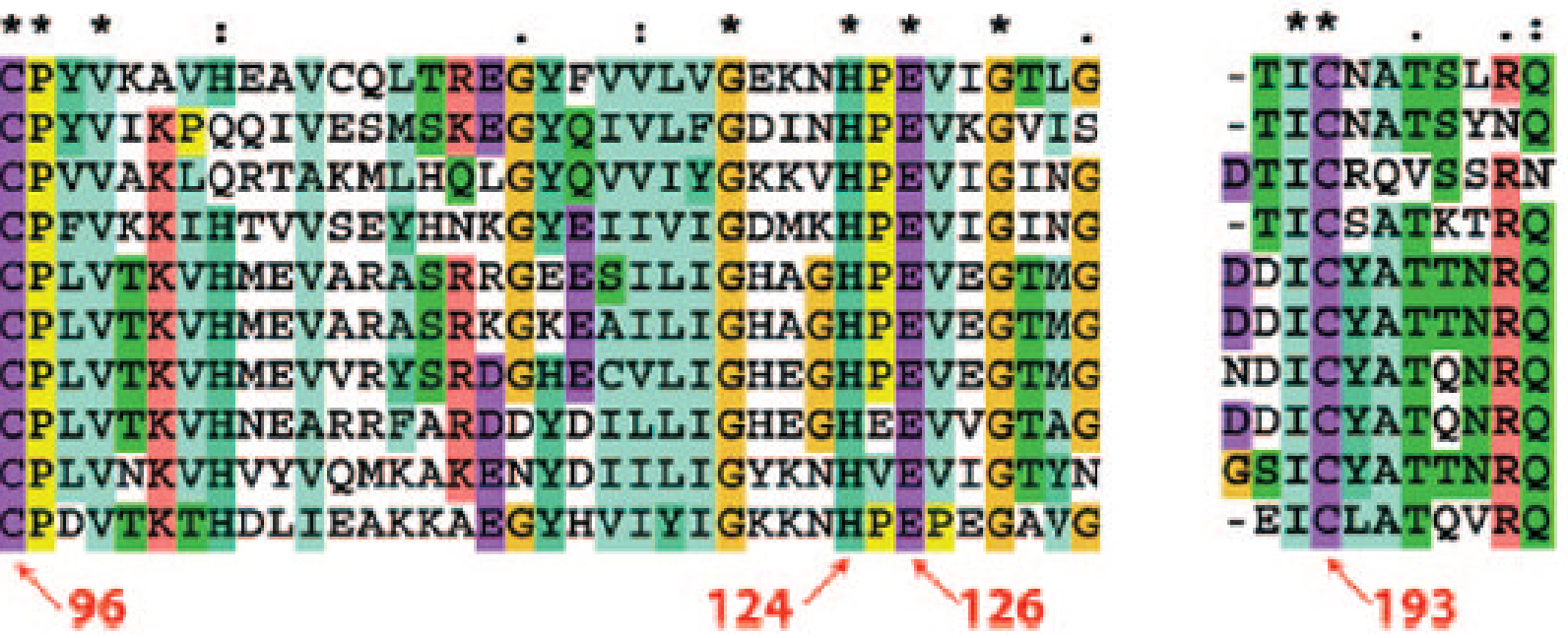

Figure 1.

Sequence alignment of LytB proteins showing conserved residues of interest obtained using the ClustalX program. ${ }^{10}$ 



Figure 2.

Structure of LytB from A. aeolicus (PDB 3DNF). (A) monomer showing cloverleaf structure consisting of three lobes, each containing alternating $\alpha / \beta$ structure, all surrounding a central $\mathrm{Fe}_{3} \mathrm{~S}_{4}$ cluster; (B) side view showing substrate accessible convex face (at left) and concave face (at right); (C) front view of protein (as in panel A), illustrating proposed substrate entry route to the $\mathrm{Fe}_{3} \mathrm{~S}_{4}$ cluster. The four residues in blue (H42, H124, T166, and S265) are very highly conserved over 224 species. The $\mathrm{Fe}_{3} \mathrm{~S}_{4}$ cluster is shown in yellow/brown and is essentially inaccessible from the rear face of the protein (D). 


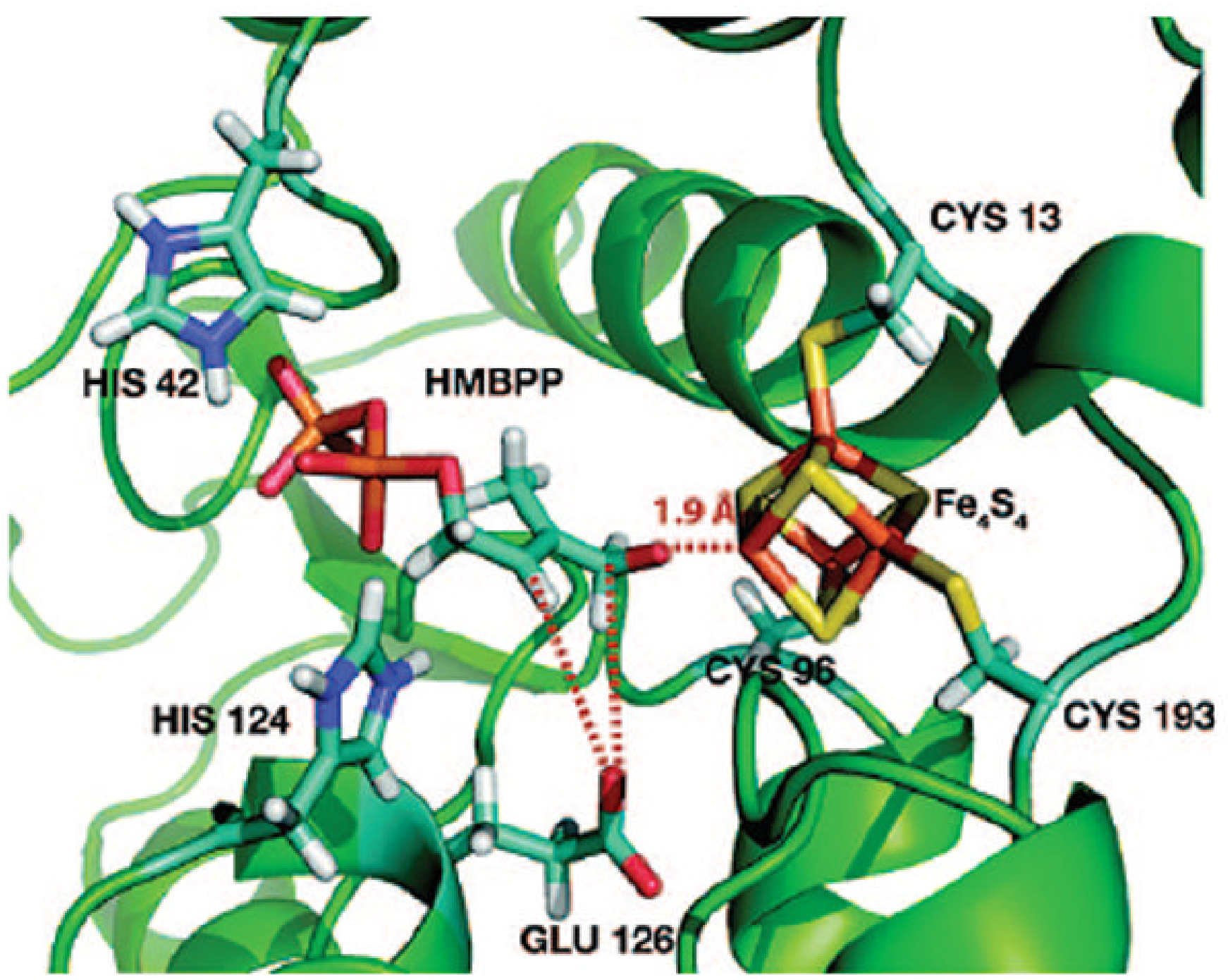

Figure 3.

Proposed ligand docking to LytB showing location of HMBPP in the central cavity, illustrating possible electrostatic interactions with His 42, His 124, and location of E126, a proton donor. We used the alkoxide of HMBPP and the diphosphate was constrained to hydrogen-bond to His42 (which is totally conserved). Glu 126 can be rotated about $C^{\alpha}-C^{\beta}$ and $C^{\beta}-C^{\gamma}$ so as to be closer to $\mathrm{C} 2$. 